\title{
Rapid detection of anti-Vaccinia virus neutralizing antibodies
}

Marit Kramski ${ }^{1,2}$, Anna Drozd ${ }^{1}$, Gregor F Lichtfuss ${ }^{1,3}$, Piotr W Dabrowski ${ }^{1}$ and Heinz Ellerbrok ${ }^{1 *}$

\begin{abstract}
Increasing infections with Monkeypox and Cowpox viruses pose a continuous and growing threat to human health. The standard method for detecting poxvirus neutralizing antibodies is the plaque-reduction neutralization test that is specific but also time-consuming and laborious. Therefore, a rapid and reliable method was developed to determine neutralizing antibody titers within twelve hours. The new assay measures viral mRNA transcription as a marker for actively replicating virus after incomplete neutralization using real-time PCR.
\end{abstract}

\section{Background}

The increasing number of humans infected with zoonotic orthopox viruses (OPV) such as Cowpox and Monkeypox virus poses a continuous and increasing threat to human health [1]. Thus, efforts to develop new vaccines against OPV infections remain important. Natural immune response and efficacy of vaccines are characterized through their capacity to induce neutralizing antibodies. The standard diagnostic method to determine OPV neutralizing antibodies in plasma or serum samples is the plaque-reduction neutralization test (PRNT). It quantifies neutralizing antibodies by measuring the reduction of virus-induced plaques where one infectious virus particle is directly related to one virus-formed plaque. PRNT is the gold standard because it is specific, direct and reproducible [2]. However the PRNT suffers from long turn-around times (several days), is laborious and uses an operator-error prone manual readout based on calculating the neutralization titer from the number of plaques counted. Due to long incubation times of the infected cell cultures necessary to allow plaque formation, anti-co-agglutinants like EDTA and plasma components can interfere with the cell monolayer and affect plaque formation, especially in low plasma dilutions. While pre-dilution of plasma might reduce these effects, it also reduces sensitivity of the PRNT and low titers of neutralizing antibodies might be missed.

\footnotetext{
* Correspondence: EllerbrokH@rki.de

'Robert Koch-Institute, Centre for Biological Safety, Nordufer 20, 13353 Berlin, Germany

Full list of author information is available at the end of the article
}

Recently, four alternative methods were described to determine neutralizing anti-Vacinia virus (VACV) antibodies using either a beta-galactosidase expressing VACV Western Reserve strain (WR) [3] or recombinant GFP expressing VACV strains $[4,5]$. Eyal et al. [6] measured remaining infectivity by enzyme immunoassay using VACV strains WR and Lister Elstree (LE). These assays are designed for large-scale screening but still are time consuming. Additionally, three of them require the use of specific recombinant VACV strains.

The assay presented here uses VACV LE and human VACV immunoglobulin (HIVIG) as a model system and quantifies neutralizing anti-VACV antibodies by combining the classic PRNT with a OPV-specific real-time PCR (designated NT-PCR) allowing quantification of replicating virus within a few hours after infection of the host cell.

\section{Results and discussion}

Validation of real-time PCR assays

To quantify actively replicating virus, three OPV-specific reverse transcriptase real-time PCR assays were established. The $\mathrm{OPV}_{12 / 13}$ assay targets the gene for the VACV LE DNA-binding phosphoprotein involved in DNA replication and nucleotide metabolism. The other two OPV-specific real-time PCR assays, D8L and Rpo18 [7], are specific for the D8L membrane protein coding region of IMV particles and the $18-\mathrm{kDa}$ RNA polymerase subunit gene, respectively. All three real-time PCR assays were OPV-specific, showed no cross-reactivity to cellular genes (data not shown) and therefore were used as a measure for replicating virus within cells. To standardize virus mRNA copies to an equal number 
of cells a cellular gene-specific c-myc real-time PCR assay was used. All assays have a linear detection range from $10^{6}$ to 10 copies per reaction with an overall $R^{2}$ of $\geq 0.98$ and PCR efficiencies $\geq 95 \%$ (table 1), which are common features for many other real-time PCR assays used in virology and microbiology [8-10]. Results of intra- and inter-assay variability for plasmids standards were less than $1 \mathrm{C}_{\mathrm{T}}$ (see details for $\mathrm{OPV}_{12 / 13}$ and c-myc assays in table 1) demonstrating a high degree of intraand inter-assay precision.

\section{Evaluation of HVIG neutralizing antibody titers with standard PRNT}

Neutralizing antibody titers of HVIG (VIG and Omrigam) were first determined with the standard PRNT. The PRNT titer is defined as the antibody dilution resulting in $50 \%$ plaque reduction. HVIG preparations were tested using $4.4 \times 10^{1} \mathrm{pfu} /$ well VACV LE and $1 \mathrm{~h}$, $2 \mathrm{~h}$ or $3 \mathrm{~h}$ of incubation for virus neutralization. For both, VIG and Omrigam, the mean neutralizing PRNT titer from three independent measurements was 1:320 one dilution step. VIG neutralizing titers varied depending on neutralization time: $1: 160(\mathrm{n}=1 / 3$ for $1 \mathrm{~h}$ neutralization, $\mathrm{n}=1 / 3$ for $2 \mathrm{~h}$ neutralization), 1:320 $(\mathrm{n}=2$ / 3 for $1 \mathrm{~h}, 2 \mathrm{~h}$ and $3 \mathrm{~h}$ neutralization) and 1:640 $(\mathrm{n}=1 / 3$ for $3 \mathrm{~h}$ neutralization). The PRNT titer for Omrigam was always 1:320 ( $\mathrm{n}=3$ for $1 \mathrm{~h}, 2 \mathrm{~h}$ and $3 \mathrm{~h}$ of neutralization). As both HVIG showed the same neutralizing activity in the PRNT, VIG was used for establishment of the NT-PCR assay for reason of availability.

\section{The NT-PCR assay}

The NT-PCR assay principle is based on measuring actively replicating VACV LE by quantifying virus mRNA levels in infected Vero E6 cells. Since cell numbers per well, RNA integrity and quantity can vary all virus copy numbers were normalized against $10^{6}$ copies of the cellular reference gene transcript of c-myc. The c-myc gene is expressed constitutively and independently from experimental conditions and sample treatment, different cell types and developmental stages. It is not affected by the infection with different OPVs (A. Nitsche, personal communication). After pre-incubation of VACV LE with VIG fewer cells became infected compared to VACV LE alone resulting in a decreased virus mRNA copy number due to neutralization of infectious virus. For VACV LE incubated with negative human serum virus mRNA copy numbers were set to $100 \%$. Based on the mRNA copy numbers determined for each antibody dilution the percentage of replicating virus was calculated in comparison to the $100 \%$ expression in virus control sample.

For the NT-PCR assay virus concentrations of $4.4 \times$ $10^{1}, 2.2 \times 10^{2}$ and $4.4 \times 10^{2} \mathrm{pfu} /$ well were tested using experimental conditions similar to the standard PRNT with $1 \mathrm{~h}$ neutralization time and $24 \mathrm{~h}$ for infection and replication in order to compare both assays. Using $4.4 \times$ $10^{1}$ and $2.2 \times 10^{2} \mathrm{pfu} /$ well of VACV LE, levels of viral mRNA were below detection threshold of the OPV $12 / 13$ real-time PCR assay $\left(<10^{1}\right.$ copies) for antibody dilutions 1:40-1:80. For antibody dilutions $\geq 1: 160$ copy numbers varied between $10^{1}$ and $10^{3}$ copies. No correlation between virus replication and antibody dilution was observed. In contrast, when using a virus dose of $4.4 \times$ $10^{2} \mathrm{pfu} /$ well, $\geq 10^{1} \mathrm{OPV}_{12 / 13}$ copies were detected for all antibody dilutions tested. A significant increase of virus replication could be detected for an antibody dilution of $\geq 1: 640$. Therefore, an infectious dose of $4.4 \times 10^{2} \mathrm{pfu}$ was selected for further experiments.

Table 1 Variability and efficiency of $\mathrm{OPV}_{12 / 13}$ and c-myc real-time PCR assays

\begin{tabular}{|c|c|c|c|c|c|}
\hline \multirow[t]{2}{*}{ PCR Assay } & \multirow[t]{2}{*}{ copy no. } & \multicolumn{2}{|c|}{ Variability* $\mathrm{C}_{\mathrm{T}}$} & \multirow[t]{2}{*}{$\mathrm{R}^{2} * *$} & \multirow{2}{*}{$\begin{array}{c}\text { PCR Efficiency } \\
\text { (\%) ** }\end{array}$} \\
\hline & & intra-assay & inter-assay & & \\
\hline \multirow[t]{6}{*}{$\mathrm{OPV}_{12 / 13}$} & $10^{6}$ & $17.58 \pm 0.23$ & $17.42 \pm 0.20$ & 0.99 & 96.00 \\
\hline & $10^{5}$ & $20.33 \pm 0.16$ & $20.55 \pm 0.20$ & & \\
\hline & $10^{4}$ & $24.13 \pm 0.15$ & $24.34 \pm 0.21$ & & \\
\hline & $10^{3}$ & $27.01 \pm 0.08$ & $27.42 \pm 0.41$ & & \\
\hline & $10^{2}$ & $31.22 \pm 0.08$ & $31.24 \pm 0.38$ & & \\
\hline & $10^{1}$ & $34.42 \pm 0.05$ & $34.96 \pm 0.47$ & & \\
\hline \multirow[t]{6}{*}{ c-myc } & $10^{6}$ & $19.63 \pm 0.04$ & $19.74 \pm 0.46$ & 0.99 & 97.62 \\
\hline & $10^{5}$ & $23.23 \pm 0.28$ & $23.09 \pm 0.31$ & & \\
\hline & $10^{4}$ & $26.40 \pm 0.05$ & $26.61 \pm 0.29$ & & \\
\hline & $10^{3}$ & $29.53 \pm 0.02$ & $29.65 \pm 0.55$ & & \\
\hline & $10^{2}$ & $34.73 \pm 0.49$ & $33.76 \pm 0.97$ & & \\
\hline & $10^{1}$ & $36.74 \pm 0.36$ & $36.39 \pm 0.58$ & & \\
\hline
\end{tabular}

* for the determination of the intra-assay variability, plasmid standards ( $10^{6}-10^{1}$ plasmid copies) were measured in triplicate, and for the inter-assay variability, measurements were repeated on 3 consecutive days; ${ }^{* *}$ calculation using the slope of the calibration curves for plasmid standards ( $10^{1}-10^{6}$ plasmid copies); The linear detection range is $10^{6}-10^{1}$ copies per run. $C_{\mathrm{T}}$ threshold cycle. 
To reduce handling time, neutralization efficacy was evaluated after $1 \mathrm{~h}, 2 \mathrm{~h}$ and $3 \mathrm{~h}$ of co-incubation of VACV LE with the VIG antibodies. For $1 \mathrm{~h}$ and $3 \mathrm{~h}$ of co-incubation no significant correlation was detected due to high variability of virus replication for all antibody dilutions. After $2 \mathrm{~h}$ a significant increase of virus replication was observed correlating with increasing antibody dilution. Virus mRNA copy numbers revealed $\leq 3 \times 10^{2} \mathrm{OPV}_{12 / 13}$ copies for antibody dilutions $<1: 640$ whereas copy numbers for dilutions $\geq 1: 640$ increased at least twofold (data not shown). A visual cut-off was set for a dilution of 1:640 and neutralization time of $2 \mathrm{~h}$ was chosen for further validation.

While a complete replication cycle of OPV takes between 9 and $24 \mathrm{~h}[11,12]$, early gene expression is detectable by real-time PCR less than $30 \mathrm{~min}$ after infection [13]. In initial experiments virus was allowed to replicate for $24 \mathrm{~h}$ to ensure one complete replication cycle. However, to reduce assay time, expression of viral genes was evaluated after $5 \mathrm{~h}$ and $7 \mathrm{~h}$ of virus infection. Additionally to the $\mathrm{OPV}_{12 / 13}$ assay, two other real-time PCR assays (Rpo18, D8L) were tested simultaneously. While all three assays target genes highly conserved between OPV species only OPV $12 / 13$ and Rpo18 target genes directly involved in virus replication. Although all tested OPV-specific real-time PCR assays have similar characteristics in terms of sensitivity, amplification efficiency and specificity no significant correlation between antibody dilution and virus neutralization could be seen with the D8L real-time PCR assay (data not shown). Thus, the D8L assay was not used for further experiments. In contrast, after $7 \mathrm{~h}$ but not after $5 \mathrm{~h}$ of virus replication, the Rpo18 and $\mathrm{OPV}_{12 / 13}$ real-time PCR assays were successfully and consistently detecting increased viral mRNA levels for antibody dilutions $\geq$ $1: 1280$ and 1:640, respectively, indicating reduced virus neutralization. Using the $\mathrm{OPV}_{12 / 13}$ and Rpo18 assay a significant correlation between antibody dilution and virus replication was detected. The results for $\mathrm{OPV}_{12 / 13}$ and Rpo 18 suggest that it is important to use a realtime PCR that targets a gene directly involved in virus replication. As the $\mathrm{OPV}_{12 / 13}$ assay was originally designed to detect the DNA binding phosphoprotein of VACV the $O P V_{12 / 13}$ and an infection time of $7 \mathrm{~h}$ was selected for further validation of the NT-PCR.

To ensure a qualitative and repetitive readout, the neutralizing antibody titer (= NT-PCR titer) was calculated based on a plot of the antibody dilution versus percentage of virus replication: the point at which the curve becomes near-horizontally (the slope approaches a near-zero value) defines the NT-PCR titer (Figure 1). This point is characterized by incomplete virus neutralization with significant increase in virus replication as a result of antibody dilution. Mathematically this point can be identified by defining the titration curve as a combination of two linear segments (lower than dilution $\mathrm{x}$ (segment $\mathrm{a}$ ) and higher than dilution $\mathrm{x}$ (segment $\mathrm{b})$ ) and using linear regression to identify the intersection (dilution $\mathrm{x}$ ) that leads to the best fits on both segments: The intersection (dilution $\mathrm{x}$ ), that results in the best linear fit (R2) on both modeled linear segments (= highest $R 2 a+R 2 b)$, defines the NT-PCR titer.

Intra-assay variation of the NT-PCR was determined based on four runs performed in parallel. To evaluate inter-assay variability the NT-PCR assay was performed on four different days. Calculation of the NT-PCR titer was performed for a total of seven assays (table 2). The NT-PCR is designed as a single well format assay and measures the inhibition of virus replication for a particular antibody dilution in one well. However, to decrease the variability between samples on the same plate the actual NT-PCR titer was calculated using the means of \% virus replication of either two (for 5 out of 7 assays), three (for 1 out of 7 assays) or four (for 1 out of 7 assays) single wells which were set up in parallel and treated identically. Comparison of the cut-off values (= NT-PCR titer) resulted in an intra- and inter-assay variability of 1:640 \pm one dilution step (table 2, Figure 2) independent of the number of single wells used to calculate the mean value. Statistical analysis indicates that dilutions from 1:40 to 1:640 where not significantly different to each other. However, all individual dilutions between 1:40 and 1:640 are significantly different to dilutions $\geq 1: 640$. This further shows that the introduction of a quantitative PCR allows the reliable calculation of a neutralizing antibody titer that is not exclusively based on a visual readout as in the case of the PRNT assay which might be subject to operator error.

To explore the NT-PCR assay's application for clinical use, serum samples of six individuals recently vaccinated with VACV LE were tested using both, PRNT and NTPCR. As only small serum volumes were available, serial dilution of serum was started at 1:40. For two of the six serum samples the outcome was identical in both tests (table 3). However, the NT-PCR and PRNT titers for three serum samples differed between one and two dilution steps still in the range of normal cell culture assay variability. Patient sample no. 6 was considered to be an outlier, as neutralizing antibody titers determined with both assays could not be confirmed due to lack of sample volume. Neutralizing titers are not identical as both assays have a different readout and definition of the cut-off of the titer. Moreover, the limited number and small sample volumes of sera available prevented further evaluation of the NTPCR assay as well as statistical comparison.

Although further evaluation with clinical samples is needed this preliminary evaluation indicates that it will be suitable for routine diagnostic use especially if results 


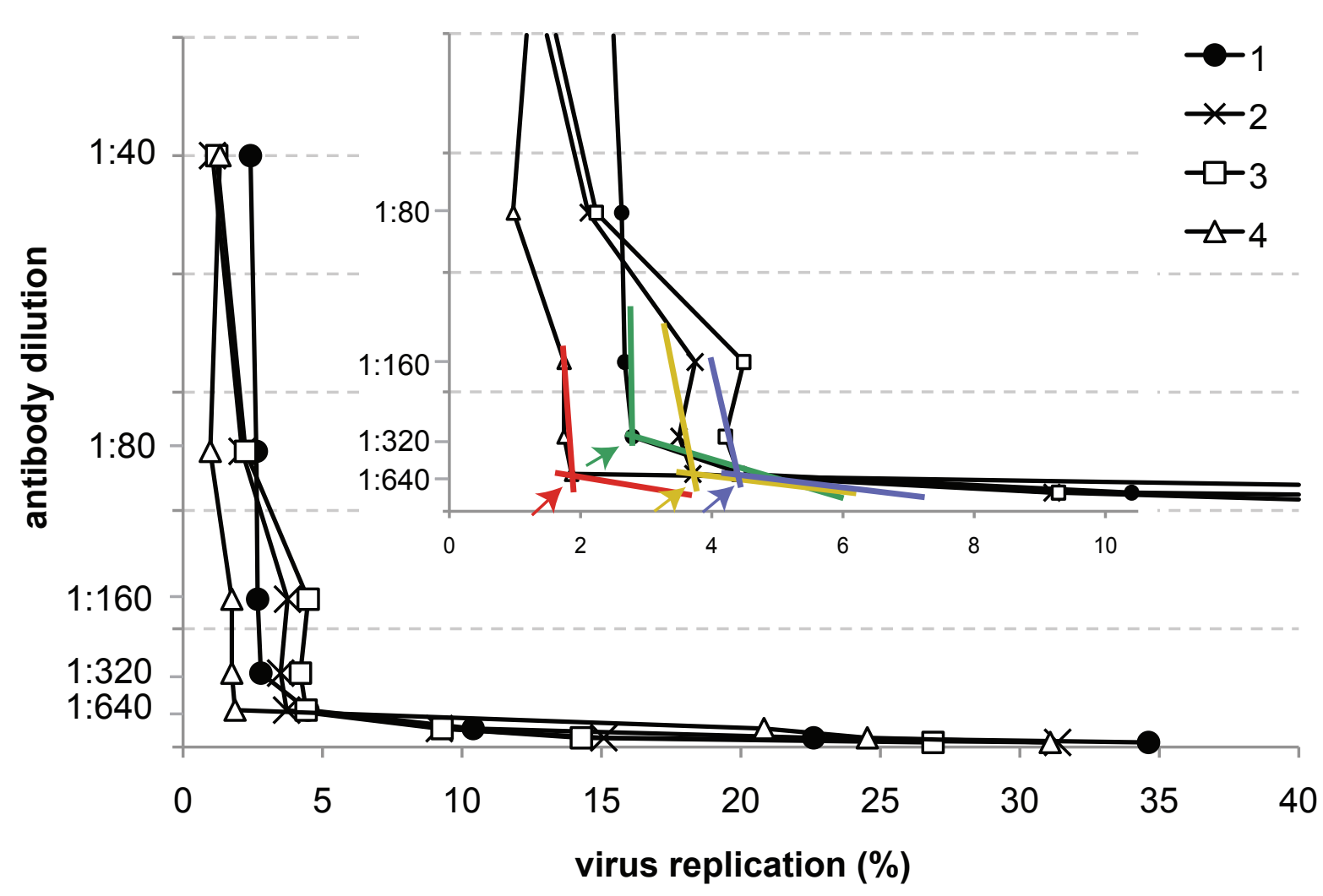

Figure 1 Graphical illustration of deriving the NT-PCR neutralizing titer in a normal analytical setting. Instead of performing statistical analysis of multiple runs (as in figure 2) the point at which the slope of the curve shows a sudden decrease to a near-zero value identifies the point of significant increase of virus replication caused by incomplete virus neutralization (if antibody dilution is plotted against percent virus replication) and defines the neutralizing antibody titer. Mathematically, this point can be derived by treating the curve as a composition of two near-linear fragments (colored curves). The intersection (arrows in enlarged insert), which results in the best linear fit (R2) on both modeled linear segments (= highest R2a+R2b) defines the NT-PCR titer. Numbers indicate curves derived from different number of replicates per run: \#1 and \#2: mean values of two wells; \#3: mean value of three wells; \#4: mean value of four wells analyzed per dilution step, respectively. Independent of the number of replicates analyzed the resulting neutralization titer was always the same, suggesting that duplicate measurements should suffice for normal clinical or analytical application of the NT-PCR assay.

are needed rapidly, if plasma components interfere with the cell culture or if neutralizing antibodies to viruses with no or poor cytopathic effect in cell culture (no need for the detection of plaques) need to be analyzed. It should be easily adaptable to other DNA viruses as soon as a suitable real-time PCR assay is available to detect viral mRNA. For DNA viruses the detection of viral mRNA indicates the presence of actively replicating virus in the cell limiting the potential effect of contaminating DNA from the genome of the inoculated virus just sticking to the cell surface. Also, the assay should be adaptable to RNA viruses if active virus replication could be determined and distinguished from mere contamination from viral genomic RNA. Assay conditions need to be adapted for each new virus, however, this is also true for standard PRNT assays.

Taken together, the new and rapid NT-PCR assay can be completed within $12 \mathrm{~h}$ while the turn-around time of the standard PRNT is at least 4 days. Final NT-PCR conditions are: $4.4 \times 10^{2} \mathrm{pfu} /$ well VACV LE, $2 \mathrm{~h}$ of neutralization time, $7 \mathrm{~h}$ of infection and replication time and final quantitative examination of virus mRNA copies in cells by quantitative $\mathrm{OPV}_{12 / 13}$ real-time PCR.

\section{Conclusions}

The NT-PCR assay is a fast, reliable and sensitive tool for the detection of VACV neutralizing antibodies. It will be suitable for routine diagnostic and could pose a valuable alternative to the standard PRNT assay. The low detection limit and the high degree of accuracy for the detection of replicating virus by real-time PCR resulted in high reproducibility and short assay turnaround time. This assay can be performed with all wildtype OPV strains without the need of particular VACV reporter strains. It may also be beneficial for viruses with no or poor cytopathic effect in cell culture. 
Table 2 Calculation of the neutralizing antibody titer determined with NT-PCR assay (1.) and its intra- and inter-assay variability (2.)

\begin{tabular}{|c|c|c|c|c|c|c|c|c|c|}
\hline \multicolumn{10}{|c|}{ 1. Calculation of the NT-PCR assay } \\
\hline & & \multicolumn{8}{|c|}{$\Sigma \mathrm{R}^{2}$ single well* } \\
\hline \multicolumn{2}{|c|}{ antibody dilution } & assay \# & $1^{\mathrm{a}}$ & $2^{a}$ & $3^{a}$ & $4^{a}$ & $5^{a}$ & $6^{b}$ & $7^{c}$ \\
\hline $1: 40$ & 0.0250 & & 0.25 & 0.31 & 0.27 & 0.33 & 0.22 & 0.32 & 0.31 \\
\hline $1: 80$ & 0.0125 & & 1.34 & 1.37 & 1.31 & 1.37 & 1.26 & 1.35 & 1.42 \\
\hline 1:160 & 0.0063 & & 1.44 & 1.36 & 1.28 & 1.27 & 1.30 & 1.23 & 0.71 \\
\hline $1: 320$ & 0.0031 & & 1.61 & 1.52 & 1.45 & 1.49 & 1.17 & 1.44 & 1.11 \\
\hline $1: 640$ & $\underline{0.0016}$ & & 1.20 & 1.77 & 1.65 & 1.73 & $\underline{1.41}$ & 1.65 & $\underline{1.43}$ \\
\hline $1: 1280$ & $\overline{0.0008}$ & & 1.23 & $\overline{1.34}$ & 1.30 & 1.54 & 1.30 & 1.41 & 1.06 \\
\hline $1: 2560$ & 0.0004 & & 1.24 & 1.36 & 1.39 & 1.38 & 1.31 & 1.46 & 1.26 \\
\hline $1: 5120$ & 0.0002 & & 0.25 & 0.31 & 0.27 & 0.33 & 0.22 & 0.32 & 0.31 \\
\hline
\end{tabular}

2. Inter-and intra-assay precision

\begin{tabular}{|c|c|c|c|c|c|c|c|c|c|}
\hline & \multicolumn{8}{|c|}{ respective NT-PCR titer for each assay } & \multirow{3}{*}{$\frac{\text { inter-assay variability }}{1: 640 \pm \text { one dilution }}$} \\
\hline & \multicolumn{2}{|c|}{ day 1} & \multicolumn{2}{|c|}{ day 2} & \multicolumn{2}{|c|}{ day 3} & \multicolumn{2}{|c|}{ day 4} & \\
\hline & assay 1 & $1: 320$ & assay 3 & $1: 640$ & assay 4 & $1: 640$ & assay 5 & $1: 640$ & \\
\hline & assay 2 & $1: 640$ & & & & & & & \\
\hline & assay 6 & $1: 640$ & & & & & & & \\
\hline & assay 7 & $1: 640$ & & & & & & & \\
\hline
\end{tabular}

${ }^{*} R^{2}$ is the R-squared value (R-squared value is the fraction of the variance in the data that is explained by a regression); $\Sigma R^{2}$ is the sum of $R 1^{2}$ and $R 2^{2}$; single well sample 1-7: ${ }^{a}$ mean value resulting from two wells; ${ }^{b}$ mean value resulting from three wells; ${ }^{c}$ mean value resulting from four wells; NT-PCR antibody titer is highlighted in bold and underlined and corresponds to the highest $\Sigma R^{2}$.

\section{Methods}

Cells, viruses and antibodies

VACV LE was propagated in Hep2 cells (ECACC: 86030501). Vero E6 cells (ECACC: 85020205) were used for virus stock titrations, for standard PRNT and NTPCR. Overlay medium was $1.6 \%$ carboxymethylcellulose $(\mathrm{CMC})$. All cells were maintained according to ECACC recommendations.

VACV LE (Bavarian Nordic, Martinsried, Germany) $\left(4.4 \times 10^{8} \mathrm{pfu} / \mathrm{mL}\right)$, human Vaccinia virus immunoglobulin (HVIG) (VIG antibodies, BER/FDA Bethesda, MD, USA and Omrigam 5\%, G2H50CN HO4021, Israel, 2003) and sera from six individuals vaccinated with VACV LE were used. All sera were tested for absence of cytotoxicity.

\section{PRNT}

For standard PRNT $8.5 \times 10^{4}$ cells/well of Vero E6 cells were seeded into 48-well plates and incubated over night. HVIG and sera were twofold serially diluted in cell culture medium from 1:40 to 1:2560 and mixed with an equal volume of VACV LE to $4.4 \times 10^{1} \mathrm{pfu} / 100 \mu \mathrm{L}$. Medium served as negative control. After $1 \mathrm{~h} 100 \mu \mathrm{L}$ of serum-virus mixture was added to cells in $100 \mu \mathrm{L}$ cell culture medium. Plates were centrifuged (15 min, $200 \times$ g) and virus was allowed to adsorb for $1 \mathrm{~h}$ at $37^{\circ} \mathrm{C}$. Next, cells were overlaid with $400 \mu \mathrm{L}$ overlay medium and

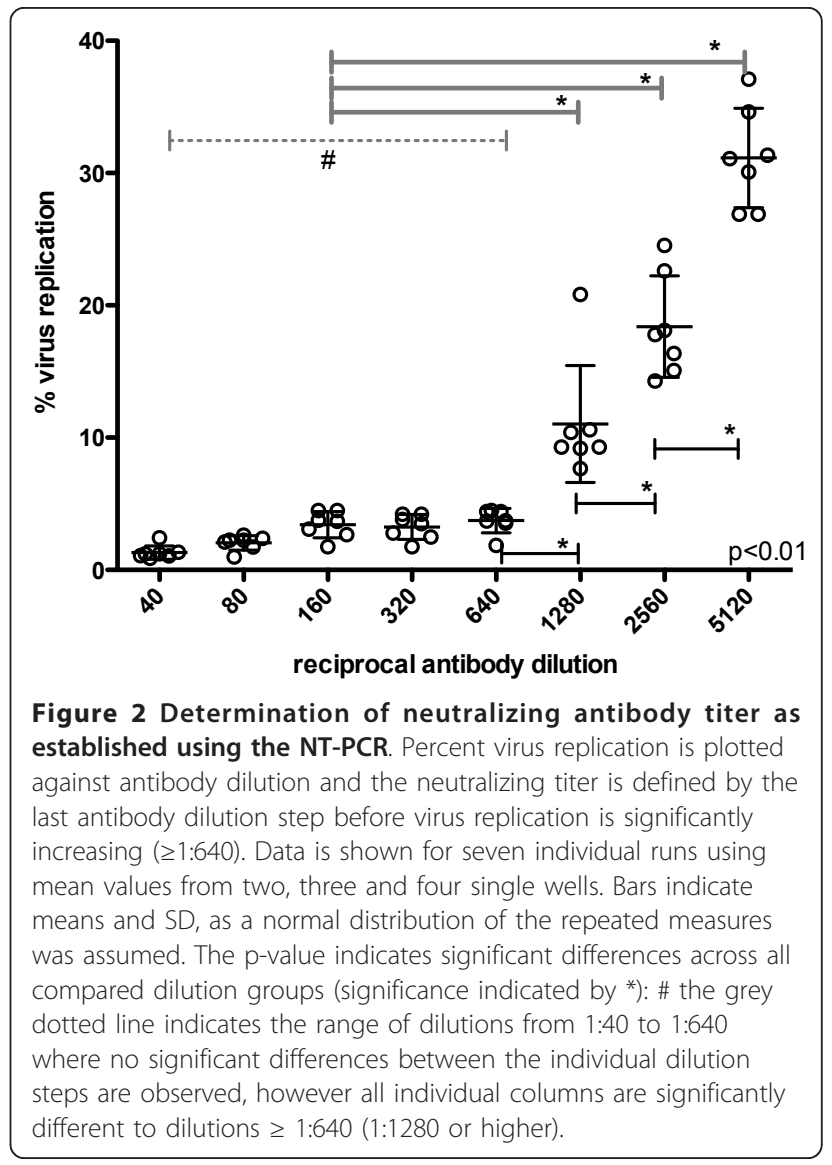


Table 3 Serum samples from VACV LE vaccinated individuals analyzed by PRNT and NT-PCR

\begin{tabular}{ccc}
\hline Patient \#* & NT-PCR titer & PRNT titer \\
\hline 1 & $1: 80$ & $1: 40$ \\
2 & $1: 160$ & $1: 40$ \\
3 & $1: 160$ & $1: 160$ \\
4 & $1: 320$ & $1: 640$ \\
5 & $1: 40$ & $1: 40$ \\
$6^{\S}$ & $1: 640$ & $1: 40$ \\
\hline
\end{tabular}

* lowest dilution step was 1:40, bigger volumes of serum were not available. $\S$ result for this patient is considered as outlier (PRNT was done only once because of lack of serum availability).

incubated for 4 days. Medium was aspirated and cells were fixed with $4 \%$ formaldehyde for $30 \mathrm{~min}$, stained with naphthalen blue black and washed once with tap water. Plaques were counted and the titer for $50 \%$ plaque reduction was calculated referred to $\mathrm{VACV}$-negative serum.

\section{NT-PCR assay}

To optimize the NT-PCR assay, three VACV LE concentrations $\left(4.4 \times 10^{2}, 2.2 \times 10^{2}\right.$ and $4.4 \times 10^{1} \mathrm{pfu} /$ well $)$, a neutralization time between $1 \mathrm{~h}, 2 \mathrm{~h}$ and $3 \mathrm{~h}$, total incubation time for virus entry and initial replication of $24 \mathrm{~h}$, $7 \mathrm{~h}$ or $5 \mathrm{~h}$ and three different viral target sequences for OPV-specific real-time PCR were investigated. All other preceding steps were performed according to the standard PRNT. After incubation, medium was aspirated and cells were washed with PBS, trypsinized, washed twice with PBS and centrifuged $(5 \mathrm{~min}, 250 \times \mathrm{g})$. Cell pellet was immediately resuspended in $700 \mu \mathrm{L}$ RLT buffer and RNA was extracted using the RNeasy Mini Kit (Qiagen, Hilden, Germany) according to the manufacturer's protocol. Residual DNA was eliminated by DNase treatment (Turbo DNase Kit; Ambion, Hamburg, Germany). cDNA was synthesized in a total volume of $20 \mu \mathrm{L}$ containing 500 ng Oligo $\mathrm{dT}_{(18)}$ primer, 500 ng calf thymus DNA and $10 \mu \mathrm{L}$ RNA. No RNase inhibitors were added as all RNA samples were processed immediately after extraction. After $5 \mathrm{~min}$ at $65^{\circ} \mathrm{C}$ a mix consisting of $4 \mu \mathrm{L} 5 \times$ buffer, 2 $\mu \mathrm{L} 0.1 \mathrm{M} \mathrm{DTT}, 0.4 \mu \mathrm{L} 25 \mathrm{mM}$ dNTP and $200 \mathrm{U}$ Superscript II reverse transcriptase (Invitrogen, Karlsruhe, Germany) was added.

Samples were incubated at $37^{\circ} \mathrm{C}$ for $50 \mathrm{~min}$ and at $70^{\circ} \mathrm{C}$ for $15 \mathrm{~min}$. For each RNA sample a reverse transcription (RT) control reaction was performed replacing the reverse transcriptase water to verify absence of contaminating DNA. Quality of cDNAs was tested using the cmyc real-time PCR assay which simultaneously served as control of RNA extraction and cDNA synthesis. Only cDNA with $\mathrm{C}_{\mathrm{T}}$ values $\geq 10^{4}$ c-myc copies per reaction were further analyzed. Four real-time PCR assays targeting different viral genes (table 4) were established and tested to quantify VACV gene expression as indicator for active virus replication. The respective amplicons of all real-time PCRs were cloned into PCR2.1 vector, according to the manufacturer's instructions (TOPO TA Cloning Kit, Invitrogen, Karlsruhe, Germany). Plasmids were purified, copy numbers calculated and tenfold serially diluted in a background of $1 \mathrm{ng} / \mu \mathrm{L} \lambda$ DNA (Fermentas, St. Leon-Rot, Germany). Samples were measured in

Table 4 Details of oligo nucleotides used in PCR reactions

\begin{tabular}{|c|c|c|c|c|}
\hline Oligo name & Oligonucleotide sequence $5^{\prime} \rightarrow 3^{\prime}$ & S/A & Ta $\left({ }^{\circ} \mathrm{C}\right)$ & $\operatorname{Tm}\left({ }^{\circ} \mathrm{C}\right)$ \\
\hline c-myc & & & 60.0 & \\
\hline c-myc F & GCCAGAGGAGGAACGAGCT & S & & 59.4 \\
\hline c-myc R & GGGCCTITCATTGTITCCA & A & & 54.2 \\
\hline c-myc TM & F-TGCCCTGCGTGACCAGATCC-T & S & & 65.9 \\
\hline $\begin{array}{l}\mathrm{OPV}_{12 / 13} / \mathrm{MPXV} \\
82 \text { protein }\end{array}$ & & & 62.0 & \\
\hline OPV F & GCCAATTGTCTTTCTCTTTIACTGA & S & & 56.2 \\
\hline OPV R & GAAAACATTTAAGGATGAATCCATCT & A & & 55.4 \\
\hline OPV TMGB & F-CCTTCTATAGATCTGAGAAT NQF MGB & S & & 65.5 \\
\hline rpo18/polymerase ${ }^{\#}$ & & & 60.0 & \\
\hline rpo18 F & CTGTAGTTATAAACGTTCCGTGTG & $S$ & & 50.7 \\
\hline rpo $18 \mathrm{R}$ & TTATCATACGCATTACCATTTCGA & A & & 47.0 \\
\hline rpo18 TM & F-ATCGCTAAATGATACAGTACCCGAAXTCTCTACT-PH & & & \\
\hline D8L/IMV membrane protein & & & 60.0 & \\
\hline D8L F & GGATGTTCTATATACGGGGATGAGTAG & S & & 57.9 \\
\hline D8L R & AAAGTTAATAAGGTAGATGACACGTTCT & A & & 58.5 \\
\hline D8L TM & F-TTCTCATCATCAGAATAAA-NFQ MGB & $\mathrm{S}$ & & 65.1 \\
\hline
\end{tabular}

$\mathrm{Y}=\mathrm{C}$ or $\mathrm{T}, \mathrm{B}=\mathrm{C}$ or $\mathrm{G}$ or $\mathrm{T}, \mathrm{W}=\mathrm{A}$ or $\mathrm{T}, \mathrm{F}=\mathrm{FAM}$ label, $\mathrm{T}=\mathrm{TAMRA}$ label, $\mathrm{TM}=$ hydrolysis probe, $\mathrm{TMGB}=$ hydrolysis probe coupled to an $\mathrm{MGB}$ moiety; $\mathrm{MGB}=$ Minor Groove Binder, NFQ = Non-fluorescent quencher, Tm = Melting temperature (calculated by nearest neighbor method), Ta = Annealing temperature, $A=$ antisense orientation, $S=$ sense orientation, \# [7]. 
duplicate and mean $C_{T}$ values were used to calculate copy numbers using 7900 and 7500 real-time PCR instruments (Applied Biosystems, Darmstadt, Germany). The $25 \mu \mathrm{L}$ reaction volume included $2 \mu \mathrm{L}$ cDNA or plasmid DNA, $2.5 \mu \mathrm{L} 10 \times$ buffer, $2.0 \mu \mathrm{L} \mathrm{MgCl}_{2}(50 \mathrm{mM}), 1 \mu \mathrm{L}$ dNTP ( $25 \mathrm{mM}$ each), $0.75 \mu \mathrm{L}$ of forward and reverse primers $(10 \mu \mathrm{M}), 0.25 \mu \mathrm{L}$ probe $(10 \mu \mathrm{M}), 0.25 \mu \mathrm{L}$ ROX (100 $\mathrm{mM}), 1$ U Platinum Taq polymerase (Invitrogen, Karlsruhe, Germany) and $15.3 \mu \mathrm{L}$ water. Cycling conditions were $2 \mathrm{~min}$ at $50^{\circ} \mathrm{C}, 10 \mathrm{~min}$ at $95^{\circ} \mathrm{C}$, followed by 45 cycles of $15 \mathrm{sec}$ at $95^{\circ} \mathrm{C}$ and $30 \mathrm{sec}$ at $60^{\circ} \mathrm{C}\left(62^{\circ} \mathrm{C}, \mathrm{OPV}_{12 / 13}\right)$.

Statistical analyses were done using GraphPad's Prism software (Version 5.0a) and a repeated measures ANOVA test and "Tukey's Multiple Comparison Test" was used for statistical analysis and p-value $\leq 0.05$ was regarded as significant.

\section{List of Abbreviations}

HVIG: human Vaccina virus immunoglobulin, OPV: orthopox virus, PRNT: plaque-reduction neutralization test, VACV: Vaccinia virus, VACV LE: Vaccinia virus Lister Elstree

\section{Acknowledgements}

The study was funded by the German Federal Ministry of Health (Foko 1121-42261). The authors are grateful to Andreas Nitsche for help in designing real-time PCR assays, to Janine Reiche and Jung-Won SimBrandenburg for excellent technical assistance, and to Ursula Erikli for copy editing.

\section{Author details}

'Robert Koch-Institute, Centre for Biological Safety, Nordufer 20, 13353 Berlin, Germany. ${ }^{2}$ Department of Microbiology and Immunology, University of Melbourne, Royal Parade, Parkville, 3206 VIC, Australia. ${ }^{3}$ Burnet Institute, 85 Commercial Road, Melbourne, Australia.

\section{Authors' contributions}

MK made substantial contributions to the study design, participated in data acquisition, analysis and interpretation and drafted and revised the manuscript critically. AD was mainly responsible for data acquisition and analysis and for interpretation of data. GFL was involved in data analysis and in discussing the manuscript. PWD participated in data analysis and interpretation. HE made substantial contributions to conception and design of the experiment and in revising the manuscript. All authors read and approved the final manuscript.

\section{Competing interests}

The authors declare that they have no competing interests.

Received: 22 November 2010 Accepted: 25 March 2011 Published: 25 March 2011

\section{References}

1. Essbauer S, Pfeffer M, Meyer H: Zoonotic poxviruses. Vet Microbiol 2010, 140:229-236

2. Orr N, Forman M, Marcus H, Lustig S, Paran N, Grotto I, Klement E, Yehezkelli $Y$, Robin G, Reuveny S, Shafferman A, Cohen D: Clinical and immune responses after revaccination of israeli adults with the Lister strain of vaccinia virus. J Infect Dis 2004, 190:1295-1302.

3. Manischewitz J, King LR, Bleckwenn NA, Shiloach J, Taffs R, Merchlinsky M, Eller N, Mikolajczyk MG, Clanton DJ, Monath T, Weltzin RA, Scott DE, Golding H: Development of a novel vaccinia-neutralization assay based on reporter-gene expression. J Infect Dis 2003, 188:440-448.

4. Cosma A, Buhler S, Nagaraj R, Staib C, Hammarin AL, Wahren B, Goebel FD, Erfle V, Sutter G: Neutralization assay using a modified vaccinia virus Ankara vector expressing the green fluorescent protein is a high- throughput method to monitor the humoral immune response against vaccinia virus. Clin Diagn Lab Immunol 2004, 11:406-410.

5. Earl PL, Americo JL, Moss B: Development and use of a vaccinia virus neutralization assay based on flow cytometric detection of green fluorescent protein. J Virol 2003, 77:10684-10688.

6. Eyal O, Olshevsky U, Lustig S, Paran N, Halevy M, Schneider P, Zomber G, Fuchs P: Development of a tissue-culture-based enzyme-immunoassay method for the quantitation of anti-vaccinia-neutralizing antibodies in human sera. J Virol Methods 2005, 130:15-21.

7. Nitsche A, Ellerbrok H, Pauli G: Detection of orthopoxvirus DNA by realtime PCR and identification of variola virus DNA by melting analysis. J Clin Microbiol 2004, 42:1207-1213.

8. Espy MJ, Uhl JR, Sloan LM, Buckwalter SP, Jones MF, Vetter EA, Yao JD, Wengenack NL, Rosenblatt JE, Cockerill FR, Smith TF: Real-time PCR in clinical microbiology: applications for routine laboratory testing. Clin Microbiol Rev 2006, 19:165-256.

9. Mackay IM, Arden KE, Nitsche A: Real-time PCR in virology. Nucleic Acids Res 2002, 30:1292-1305.

10. Wong ML, Medrano JF: Real-time PCR for mRNA quantitation. Biotechniques 2005, 39:75-85.

11. Joklik WK, Becker Y: The Replication and Coating of Vaccinia DNA. J Mol Biol 1964, 10:452-474.

12. Salzman NP, Shatkin AJ, Sebring ED, Munyon W: On the replication of vaccinia virus. Cold Spring Harb Symp Quant Biol 1962, 27:237-244.

13. Nitsche A, Stern D, Ellerbrok H, Pauli G: Detection of infectious poxvirus particles. Emerg Infect Dis 2006, 12:1139-1141.

doi:10.1186/1743-422X-8-139

Cite this article as: Kramski et al:: Rapid detection of anti-Vaccinia virus neutralizing antibodies. Virology Journal 2011 8:139.

\section{Submit your next manuscript to BioMed Central and take full advantage of:}

- Convenient online submission

- Thorough peer review

- No space constraints or color figure charges

- Immediate publication on acceptance

- Inclusion in PubMed, CAS, Scopus and Google Scholar

- Research which is freely available for redistribution

Submit your manuscript at www.biomedcentral.com/submit
Ciomed Central 